Revista lus et Praxis, Año 24, No 3, 2018, pp. 803 - 816

ISSN 0717 - 2877

Universidad de Talca - Facultad de Ciencias Jurídicas y Sociales Aborto, deferencia y activismo judicial: Comentario de la sentencia del

Tribunal Constitucional rol No 3729-2007, de 28 de agosto de 2017 Felipe Paredes

Trabajo recibido el 12 de noviembre de 2017 y aprobado el 14 de agosto de 2018

\title{
Aborto, deferencia y activismo judicial: Comentario de la sentencia del Tribunal Constitucional rol No 3729-2007, de 28 de agosto de $2017^{*}$
}

FeliPe PAREDES $^{* *}$

\section{Introducción}

La sentencia del Tribunal Constitucional rol No 3729-2017, que se pronuncia sobre requerimiento de inconstitucionalidad presentado en contra del proyecto de ley de despenalización de la interrupción voluntaria del embarazo en tres causales, a la postre la Ley $N^{\circ} 21.030$, pasará a la historia como un hito jurisprudencial. Se trata de un asunto que, sin duda, concitó el interés de toda la opinión pública y en el que se expresa entre nosotros de manera contundente, quizás por primera vez, la clásica tensión entre justicia constitucional y democracia. La sentencia es de una evidente complejidad y en ella se plantean varios debates dogmáticos relevantes. Desde esta perspectiva, el Tribunal Constitucional (TC) no elude ninguna de estas cuestiones, todas ellas de especial trascendencia para nuestro Derecho Constitucional. El estatuto constitucional del no nacido, los derechos sexuales y reproductivos o las técnicas apropiadas para interpretar la Constitución, son solo algunas de estas temáticas. En síntesis, el TC se pronuncia sobre dos grandes preguntas, que en la misma sentencia se denominan capítulos: a) la eventual inconstitucionalidad de la regulación contenida en el proyecto sobre la despenalización de la interrupción voluntaria en tres causales (respecto de todas y cada una de ellas; b) la eventual inconstitucionalidad de la regulación contenida en el proyecto sobre la regulación de la objeción de conciencia, como excepción al cumplimiento de sus disposiciones.

Por razones obvias, este comentario no intentará agotar todas las aristas de la sentencia de marras, sino únicamente se centrará en el segundo de estos capítulos, relativo a la objeción de conciencia. A pesar, de que el primer capítulo concentra la mayor cantidad flancos de carácter dogmático, el centro de la atención se ha

\footnotetext{
* Producto elaborado dentro del proyecto Fondecyt de iniciación a la investigación № 11150828 , "Proporcionalidad y deferencia en el control de constitucionalidad de las leyes", del cual el autor es investigador principal.

** Profesor de la Facultad de Ciencias Jurídicas y Sociales de la Universidad Austral de Chile. Abogado. Doctor en Derecho por la Universidad Pompeu Fabra (España). Correo: felipe.paredes@uach.c.
} 
concentrado en la interpretación extensiva que el TC formula de la objeción de conciencia. En estas breves páginas, se desarrollará una opinión crítica respecto de dicha interpretación, a la luz de una de las consideraciones centrales a partir de la que se construye la argumentación de la sentencia, esto es, la deferencia al legislador. Este ejercicio pone en evidencia las tensiones entre ambas ideas.

\section{La deferencia al legislador como criterio de interpretación constitu- cional}

Una nota distintiva de la sentencia es la preocupación del TC por intentar dialogar con una ciudadanía altamente interesada en el tema. Prueba de esto es la gran cantidad de intervenciones en las audiencias públicas que se llevaron a cabo durante la vista de la causa. En este mismo sentido, la sentencia se inicia con la explicación de las premisas que se utilizarán en la fundamentación de la decisión (considerandos $26^{\circ}$ al $32^{\circ}$ ). En efecto, esta sección se inicia con un reconocimiento de la complejidad que reviste el tema y cómo la existencia de posturas irreconciliables condiciona el fallo. En este punto Ilama la atención que el TC se detiene en explicar los criterios interpretativos que utilizará, dedicándole bastante tinta a uno de ellos que la doctrina ha denominado deferencia judicial al legislador ${ }^{1}$.

\subsection{El concepto de deferencia al legislador}

En Chile el debate sobre este tema fue instalado por Atria ${ }^{2}$, y después fue enriquecido por otros autores como Zapata ${ }^{3}$ y Martínez ${ }^{4}$. En la jurisprudencia existen aproximadamente tres docenas de sentencias en las que se ha citado el principio de deferencia, las que se caracterizan por una escasa fundamentación, limitándose a una invocación genérica de otros principios, como la separación de poderes y el respeto recíproco que los órganos del Estado se deben entre $s^{5}{ }^{5}$. Por el contrario, esta sentencia se avizora como una contribución mayor, pues en ella se precisa el contenido de este principio, el que estaría dado por tres elementos: a) el reconocimiento de un ámbito de discreción regulativo al legislador; b) reglas sobre cargas de la justificación de la declaración de inconstitucionalidad, lo que se traduce en la presunción de constitucionalidad

\footnotetext{
1 ZapATA (2008), p. 227.

2 Atria (1993), p. 378.

3 Zapata (2008), p. 227.

4 Martínez (2014) y Martínez (2015).

5 Martínez (2014), p. 386.
} 
de la ley, y c) un estándar de inconstitucionalidad, que se expresa en la fórmula thayeriana de la "duda razonable".

A pesar de que el voto de mayoría no utiliza explícitamente dicha expresión, en la práctica lo que hace es establecer como regla de juicio el principio de deferencia al legislador. Aquello se constata en el tipo de nomenclatura utilizada en la redacción de estos considerandos. Por ejemplo, la sentencia apela a la discreción legislativa que, si bien es un término proveniente de la teoría del Derecho, se aproxima a un concepto de la tradición dogmática del Derecho público, como es la libertad de configuración normativa del legislador. Desde esta perspectiva, en Alemania tanto Alexy ${ }^{6}$ como Klatt $^{7}$ han planteado la distinción entre discreción estructural (DES) y discreción epistémica (DEP). Dicha distinción es clave para entender el lugar de la deferencia y cada uno de sus componentes en el juicio de constitucionalidad. Según Klatt, la DES equivale a la posibilidad de elegir entre varios cursos de acción, lo que para este autor es un elemento central en la configuración de las atribuciones de los poderes legislativos en el Estado Constitucional de Derecho. De este modo, la DES consiste en el espacio de configuración normativa que la Constitución deja al legislador, es decir lo que no está, ni expresamente prohibido, pero tampoco es imperativo a la luz de las disposiciones constitucionales ${ }^{8}$. Schneider refuerza esta idea al señalar que, dentro de los límites de esta, no se produce ningún control de contenido de las decisiones del legislador por parte del Tribunal Constitucional ${ }^{9}$. Entre nosotros, este concepto ha sido desarrollado por Aldunate ${ }^{10}$ a propósito de regulaciones al derecho de propiedad.

Por otra parte, la DEP surge de los límites para conocer el Derecho y aplicarlo a un caso concreto. Ello se relaciona con otra idea invocada por el TC, sobre las cargas de justificación en el juicio de constitucionalidad, la que se materializa en la presunción de constitucionalidad de la ley. Según Ferreres, esta "impone a quien sostiene que el texto de una ley es inconstitucional la carga de argumentar convincentemente que se da una incompatibilidad entre la norma que ese texto expresa y el sistema de normas que el texto constitucional expresa", de forma tal que "cualquier duda acerca de la interpretación correcta de uno u otro texto se resolverá en favor de la ley: in dubio pro legislatore" ${ }^{\prime 11}$.

\footnotetext{
6 Alexy (2002).

7 KLATT (2007).

${ }^{8}$ Klatt (2007), p. 516.

9 SChneider (1982), p. 55.

10 Aldunate (2006), p. 300.

11 Ferreres (2012), p. 131.
} 


\section{2. ¿Qué podemos esperar de la deferencia al legislador?}

La deferencia al legislador es una de las respuestas diseñadas por la teoría contemporánea de la Constitución, para hacer frente a los cuestionamientos que aducen la falta de legitimidad de que adolece la justicia constitucional al invalidar las decisiones legislativas, ante la existencia de desacuerdos radicales acerca de los valores que protege el texto constitucional ${ }^{12}$. En síntesis, frente a ellas, el Tribunal Constitucional debería evitar sustituir el juicio del legislador por el propio, salvo que existan razones de peso que justifiquen intervenir el texto de la ley. Emparentada con esta idea se encuentra otra planteada por el mismo Kelsen, quien, al concebir las competencias propias de la justicia constitucional, afirmó que un órgano de este tipo debe limitarse a ser únicamente un legislador negativo, es decir, solo posee capacidad de veto, pero no puede añadir nada nuevo al contenido del texto sometido a su control, por ejemplo, creando un estatuto jurídico distinto del diseñado por el legislador ${ }^{13}$.

La reflexión anterior muestra que el principio de deferencia debe tener un lugar en la actividad de cualquier tribunal constitucional, pero también pone en evidencia sus peligros, al mismo tiempo que obliga a situar con precisión las coordenadas en las que puede ser utilizado. Se dice usualmente que la doctrina de la deferencia es una herramienta puesta al servicio de la autocontención judicial ${ }^{14}$, no obstante, no es difícil que esta se convierta en un buen aliado del activismo judicial. Ello puede suceder a causa de dos factores: se confunde deferencia con ausencia de control o no se justifica su uso. Sobre lo primero aquí no se ahondará, pero es importante destacar que ser deferente no es sinónimo de abdicar la función de controlar la constitucionalidad de la ley ${ }^{15}$. Lo segundo incide en que la deferencia no se puede invocar aleatoriamente, por el contrario, es imperativo que su uso esté mediado por una explicación de qué casos (materias, tipos de normas, tipos de atribuciones) requieren mayor deferencia o mayor rigurosidad en el juicio de constitucionalidad. Esto es lo que los autores denominan una teoría normativa de la deferencia.

En el Derecho comparado existen varias teorías normativas de la deferencia. Por ejemplo en EE.UU., el principal criterio de distribución ha sido ratione materiae. Aunque existen varios debates abiertos, la jurisprudencia de ese país ha identificado casos claros en los que generalmente aplica la deferencia, haciendo lo propio con materias donde, por el contrario, se utiliza

\footnotetext{
12 Waldron (2005).

13 Kelsen (1942), p. 187.

14 Posner (1983), p. 10.

15 Kanavagh (2008), p. 186.
} 
un escrutinio sumamente estricto. Un enfoque similar ha adoptado el Tribunal Europeo de Derechos Humanos con la doctrina del margen de apreciación ${ }^{16}$. La enseñanza que se puede sacar de esto es que es necesario formular una teoría normativa, aunque probablemente no sirva de mucho importar un modelo comparado, pues lo usual es que las características idiosincráticas de cada sistema son relevantes en el resultado. En cualquier caso, lo que es evidente, es que sin esta teoría normativa la deferencia puede transformarse en mero artificio retórico y derivar en un arma peligrosa.

El mejor ejemplo de ello se puede observar en la segunda parte de la sentencia comentada, donde sorprendentemente el TC se olvida que páginas atrás proclamó que la deferencia al legislador sería uno de los principios fundamentales que informaría todo su razonamiento. Por el contrario, actúa de forma contradictoria con esa declaración: examina el proyecto sin respecto a preguntarse cuál es el margen de libertad de configuración normativa del legislador y decide intervenir directa y substantivamente en el texto. Todo ello en un escenario análogo al del capítulo primero, con limitaciones epistémicas muy similares, e incluso, con la probabilidad muy alta y previsible de que esa intervención en el proyecto produzca problemas prácticos que terminen minando de forma importante lo que se resolvió previamente.

\section{Objeción de conciencia y deferencia al legislador}

La objeción de conciencia (OC) es una institución en la que merece la pena detenerse un instante en explicarla. Tradicionalmente, se ha dicho que esta es una forma de desobediencia al Derecho por razones morales. Seoane la define como "la negativa o el rechazo al cumplimiento de un deber jurídico de naturaleza personal por razones de conciencia"17. Esto muestra que es una institución que se aloja dentro del marco conceptual del derecho fundamental a la libertad de conciencia. No obstante, varias cosas deben ser tenidas en cuenta, pues es una institución que plantea algunas preguntas y dificultades.

En primer lugar, en tanto supuesto de desobediencia al Derecho, es pacífico que no puede convertirse en la regla general. Esto también obliga a distinguirla de otras hipótesis de desobediencia al Derecho, por ejemplo, la desobediencia civil, la violencia revolucionaria, o el mero comportamiento delictual. La OC permite la eximición de la aplicación de una norma invocando razones morales, sin aspirar directamente a su modificación, pero sin

\footnotetext{
16 LetSAs (2006).

17 Seoane (2009), p. 10.
} 
aceptar el castigo propio asociado al incumplimiento ${ }^{18}$. Desde esta perspectiva, es potencialmente probable que la OC produzca un conflicto de derechos, siendo el derecho a la vida y el derecho a prestaciones de salud los posibles candidatos. Por lo mismo, la autorización para invocar la OC debe ser de carácter excepcional, individual y su fundamento debe descansar en razones morales auténticas y de cierta entidad. Por último, a ella también debería aplicarse la tesis del TC del considerando 32: "los derechos fundamentales no se conciben o consagran, ni pueden protegerse de modo absoluto o ilimitado".

El proyecto de ley en cuestión, que en definitiva se convirtió en la Ley $N^{\circ} 21.030$, contenía en su redacción original una fórmula bien distinta de la que resultó de la intervención del TC. El texto en su artículo $1^{\circ} \mathrm{N}^{\circ} 3$ consagraba, con algunas restricciones, la $\mathrm{OC}$ en favor del personal médico que labora dentro del pabellón quirúrgico, de forma tal que si se ejerce este derecho: 1) el centro de salud debía poner a disposición personal de reemplazo; 2) no podía alegarse en el caso de la indicación terapéutica; 3 ) en el caso de la indicación criminógena, no podía alegarse si el vencimiento del plazo era inminente; 4) finalizaba dicha disposición con el siguiente enunciado: "la objeción de conciencia es de carácter, personal, y en ningún caso, podrá ser invocada por una institución", lo que dejaba claro el carácter exclusivamente personal de la OC.

Al proyecto se le plantearon tres clases de reproches que -con ayuda del voto de minoría de los ministros Carmona y García- sistematizamos de la siguiente manera:

a. OC ampliada (la OC debe extenderse a todo funcionario que trabaje en el centro de salud y no solo a quienes intervengan en un procedimiento dentro del pabellón quirúrgico).

$b$. OC sin excepciones (debe poder invocarse la OC en todas las causales de interrupción del embarazo, sin importar las circunstancias).

c. OC institucional (la OC debe corresponder no solo a las personas que trabajan en el sistema de salud, sino que también los centros de atención médica deben ser titulares de dicho derecho).

De estos tres reproches el TC acoge en su integridad a. y c., respecto de $b$. lo hace parcialmente, eliminando la excepción a la OC en el caso de la indicación criminógena (c. 138). Para justificar esta conclusión el voto de mayoría se apoya en el Derecho comparado, aunque esta estrategia tiene un problema, ya que los antecedentes comparados no contienen mucha información relevante acerca de si los centros de salud son titulares o no del derecho a la OC. En efecto, el caso más elocuente en tal sentido es la jurisprudencia

18 Vilajosana (2008), p. 170. 
de la Corte Interamericana de Derechos Humanos $(\mathrm{CIDH})$, pero que precisamente afirma la conclusión contraria a la que el TC elige defender, por lo que es comprensible que este afirme el carácter no vinculante de la jurisprudencia de la Corte de San José (c. 129 y 130). En cualquier caso, si ello fuera cierto, el dictamen del Tribunal Europeo de Derechos Humanos o la Constitución de Paraguay lo serían aún menos. Por otra parte, el TC no es fiel al dar cuenta de la doctrina de la $\mathrm{CIDH}$, al señalar que esta no es consistente. La verdad es que, a diferencia de lo que el TC sostiene, es pacífico que en el Sistema Interamericano las personas jurídicas carecen de derechos, salvo dos casos excepcionales, entre los que no está la OC ni los centros de salud ${ }^{19}$.

Ya más en tierra derecha y luego de explicar los fundamentos generales de la OC, anclados en la dignidad humana y la libertad de conciencia, la sentencia intenta argumentar su ampliación a todo el personal que trabaja en el centro de salud, señalando que: "no se divisa razón jurídica alguna para restringir la objeción de conciencia solamente a las personas naturales que revistan la condición de profesionales. Cuando aquéllas que no lo son también podrían tener reparos, en conciencia, frente a los procedimientos en que deben intervenir" (c. 135). A nuestro juicio ese argumento por sí solo es insuficiente, pues no da cuenta de la excepcionalidad de una institución como la OC, ni tampoco que su ejercicio potencialmente entrará en colisión con los derechos de los pacientes, lo que debería bastar para exigir condiciones rigurosas en su ejercicio. En otras palabras, sí hay razones jurídicas relevantes que acreditan que una ampliación de este tipo deba realizarse siempre con cautela.

Sin perjuicio de lo anterior, si la coherencia tiene algún valor en estas cuestiones, donde derechamente yerra el TC, es en materia de objeción de conciencia institucional. Al respecto se señala: "Que, no es menos evidente, asimismo, que la objeción de conciencia puede ser planteada legítimamente por sujetos jurídicos o asociaciones privadas, en este caso, con arreglo a la autonomía constitucional que a los grupos intermedios de la sociedad les reconoce la propia Carta Fundamental". Complementariamente, la autonomía de los grupos intermedios se liga con el derecho de asociación y con la libertad de enseñanza, de la que se deriva la posibilidad de que existan centros con idearios. En este sentido, varias consideraciones críticas pueden ser planteadas.

\subsection{Personas jurídicas y derechos fundamentales}

Primero, no es evidente que las personas jurídicas son titulares del derecho a la OC, al existir un gran desacuerdo teórico al respecto. Ello se puede

${ }^{19}$ CIDH: OC-22/15, de 26 de febrero de 2016. 
constatar del examen de distintos sistemas comparados. Por ejemplo, el Sistema Interamericano niega esta posibilidad con carácter general. A diferencia, en Europa se ha respondido afirmativamente a esta pregunta en términos parciales y con sujeción a requisitos estrictos. La doctrina de los tribunales europeos, se puede resumir en los siguientes puntos: 1) solo las personas humanas son titulares plenos de derechos fundamentales; 2) existen ciertos derechos que, por su propia naturaleza, solo corresponden a las personas humanas; 3) el resto de los derechos fundamentales puede ser atribuido a las personas jurídicas, pero para ello se requiere una vinculación directa entre la persona jurídica y el derecho fundamental, es decir, es necesario que a través de ellas se estén preservando los derechos fundamentales de sus miembros ${ }^{20}$. Por ejemplo, para el caso español señala Rosado, que la persona jurídica solo encontraría amparados aquellos derechos inmediatamente relacionados con su propia existencia ${ }^{21}$. Si esta tesis es correcta, resulta claro, por ejemplo, que un sindicato es titular del derecho de libertad sindical o que un medio de comunicación lo es de la libertad de expresión, pero no que un establecimiento de comercio pueda ampararse en la libertad de expresión para evadir las restricciones publicitarias establecidas legalmente.

Donde sí se ha aceptado con mayor amplitud la titularidad de derechos fundamentales por personas jurídicas, es en EE.UU. Si bien existe una larga tradición jurisprudencial en dicho país respecto de derechos de carácter institucional como la propiedad, el debido proceso o la libertad de prensa, en los últimos años la Corte Suprema ha reconocido a las personas jurídicas derechos que expresan facultades intelectuales propias de los seres humanos. Esta tendencia se inició con First National Bank of Boston v. Bellotti ${ }^{22}$, y en la última década se ha acrecentado con dos controvertidas sentencias: Citizens United v. FEC ${ }^{23}$ y Burwell v. Hobby Lobby Stores, Inc. ${ }^{24}$. En la actualidad, la doctrina se encuentra hondamente dividida respecto a las soluciones que emanan de dichas sentencias. Además, en ambos casos, las votaciones en dicho tribunal se resolvieron con un reñido cinco a cuatro, lo que incluso permite dudar si estas sentencias se convertirán en definitiva en un precedente estable en el sistema. Igualmente, en la justificación de estas decisiones está siempre detrás la idea de que la empresa tiene un lugar importante en la cultura social,

\footnotetext{
20 DíAz (1989), p. 100.

21 Rosado (2004), p. 165.

22435 U.S. 765 (1978).

23558 U.S. 310 (2010).

24573 U.S. _ (2014).
} 
económica y jurídica de este país. Todo ello hace difícilmente replicable esa jurisprudencia en Chile.

Por otra parte, una tesis de estas características contradice toda la jurisprudencia reciente del TC. El asunto había sido discutido en la STC rol № 2731-2014 INA, donde se afirmó: "que si bien existe consenso en la doctrina y jurisprudencia en que la tutela fundamental ofrecida por el artículo 19 puede beneficiar tanto a personas naturales como a personas jurídicas, es igualmente objeto de consenso que la protección de personas jurídicas sólo es admisible cuando la naturaleza del derecho o interés tutelado lo justifique. Lo anterior por cuanto la persona natural es la que nace libre e igual en dignidad y derechos y, por ello, es reconocida como principal y natural titular de derechos fundamentales" (c. 22). Añadiéndose a continuación que: "el reconocimiento de las personas jurídicas como titulares de derechos fundamentales suele ser excepcional y restrictivo en términos de los derechos fundamentales tutelados y en lo que respecta al sentido y alcance de los mismos" (c. 22). Sin perjuicio de lo anterior, existe otro fallo donde el TC es aún más categórico: la STC rol No 3016-16, sobre la constitucionalidad del proyecto de reforma laboral. En esta última sentencia, en el capítulo destinado a pronunciarse acerca de la titularidad del derecho a la libertad sindical, se concede absoluta primacía a los derechos de los individuos en caso de entrar en conflicto con el de las personas jurídicas, afirmando que "se trata de un derecho cuya activación o determinación originaria para ejercerlo o no reside en los trabajadores universalmente considerados" (c. 19) y más adelante agrega "el mecanismo de intermediación representación de la voluntad individual para expresar el interés común del colectivo en una negociación no puede implicar una prohibición o limitación tan drástica del derecho subjetivo de cada trabajador".

\subsection{Tribunal Constitucional y políticas públicas}

Segundo, la intervención del texto de una ley por parte del TC genera una serie de problemas prácticos en la aplicación de dicha norma, obviamente todo esto es también aplicable en sede de control preventivo en donde lo que se juzga es un proyecto de ley. Como vimos antes, uno de los factores que permite justificar la deferencia es la incertidumbre epistémica, la cual puede provenir de las limitaciones al conocimiento o del Derecho o de los hechos. Respecto de lo segundo, en EE.UU., desde la sentencia United States v. Carolene Products Co. ${ }^{25}$, se ha reconocido también la deferencia en términos fácticos. Según Solove, el fallo advirtió explícitamente que el análisis de los hechos planteaba un desafío

25304 U.S. 144 (1938). 
significativo para el control de constitucionalidad. Esto se explica porque en la época del New Deal estos juicios comenzaron a plantear complejas cuestiones relativas a regulaciones económicas y políticas públicas, en ellos las dificultades no se centraban tanto en la interpretación del Derecho ${ }^{26}$. Por el contrario, en la mayoría de las ocasiones se hacía difícil para los jueces, que tenían una formación como juristas, intervenir en decisiones que requerían de conocimientos técnicos específicos en otras áreas. Entonces, para solventar esta dificultad, la única solución que encontró la Corte Suprema fue confiar en el escrutinio de la evidencia que soportaba a la ley.

Un problema de similar magnitud se presenta en el caso de marras. La decisión de alterar un régimen jurídico, diseñado sobre la base de una política pública en materia sanitaria, genera una serie de problemas respecto de los cuales el TC no está en condiciones de responsabilizarse por su impacto. En este contexto, si el TC respetara su compromiso de ser deferente, debería haber respaldado la constitucionalidad de la ley. En efecto, no hay que emplear mucha creatividad para detectar algunos de los inconvenientes que producirá la decisión en la práctica. Entre estos podemos mencionar los siguientes:

a) Si la simplicidad y accesibilidad de la ley son virtudes democráticas, la sentencia en este punto conspira en contra de ellas, pues se crean distintos estatutos jurídicos lo que puede generar confusión entre las usuarias al solicitar una prestación de salud, al dar origen a: centros públicos y privados, centros con y sin ideario, centros con y sin objetores de conciencia. Al cruzar estas variables se multiplican las combinaciones posibles.

b) Al reconocer la OC institucional la sentencia siembra un manto de dudas sobre cómo esta se va compatibilizar con la excepción del artículo final, es decir, cuando se invoque la causal de riesgo vital y no exista otro cirujano, pues esta está pensada para la OC individual. Según como se resuelva esa cuestión, incluso, se puede afectar gravemente la lex artis, y poner en peligro la vida de las pacientes. Por otro lado, la eliminación de la excepción en el caso de la indicación criminógena puede llegar a afectar la responsabilidad penal de las usuarias, al impedirles cumplir con los plazos por causas no imputables a su hecho propio.

c) Es indudable que el ejercicio del derecho a la OC en esta materia tiene asociado un costo económico, por ejemplo, el derivado de los traslados. No resulta claro si serán las usuarias, el objetor de conciencia o el Estado quien asumirá dicho costo.

d) El reconocimiento de la $\mathrm{OCl}$ puede producir conflicto con la libertad de conciencia de los trabajadores de dichos centros. Esto puede originar

${ }^{26}$ Solove (1999), p. 992. 
vulneración de sus derechos laborales e incluso de sus derechos fundamentales en el marco de la relación laboral.

\subsection{Tribunal Constitucional y legislador positivo}

Tercero, para poder acoger una impugnación de esta naturaleza el TC no tiene otra opción que reescribir el texto de la ley, rompiendo el paradigma del legislador negativo. Al respecto, un debate importante ha sido la pertinencia de las sentencias interpretativas. En ocasiones, con el propósito de preservar la ley, el TC ha dictaminado su constitucionalidad, bajo condición de que esta sea interpretada de una determinada manera. A favor se ha dicho que es preferible conservar la ley que declararla inconstitucional. En contra se ha dicho que al TC le corresponde aplicar e interpretar la Constitución y la interpretación de la ley es competencia de los tribunales ordinarios, principalmente, de la Corte Suprema a través del recurso de casación. Pues bien, en este caso el TC es incluso mucho más osado, yendo más allá de una sentencia interpretativa, reescribiendo derechamente el texto en términos positivos.

La disposición del proyecto: "la objeción de conciencia es de carácter, personal, y en ningún caso, podrá ser invocada por una institución", se ve completamente alterada con la eliminación de las palabras "en ningún caso". Si el TC hubiese sido coherente con la idea de la deferencia no debería haber acogido la impugnación, pues para poder hacerlo, falta a su promesa de garantizar un margen de libertad de configuración normativa al legislador. Muy por el contrario, sustituye a este en el ejercicio de la función legislativa, adopta una decisión en términos substantivos, comprometiendo el esquema basado en el principio de separación de poderes sobre el que se construye toda la arquitectura del Estado constitucional y democrático de Derecho de nuestros días.

\section{BIBLIOGRAFÍA CITADA}

AldunAte, Eduardo (2006): "Limitación y expropiación: Scilla y Caribdis de la dogmática constitucional de la propiedad", en: Revista Chilena de Derecho (No 33, Vol. 2), pp. 285-303.

Alexy, Robert (2002): "Epílogo a la Teoría de los derechos fundamentales", en: Revista Española de Derecho Constitucional (Año 22, № 66), pp. 13-64.

ATRIA, Fernando (1993): "El Tribunal Constitucional y la objeción democrática", en: Revista Chilena de Derecho (№ 2, Vol. 20), pp. 367-378.

DíAz, Juan (1989): “¿Tienen derechos fundamentales las personas jurídicas?", en: Revista de Administración Pública (№ 120), pp. 79-126. 
FeRRERES, Víctor (2012): Justicia constitucional y democracia, 2a edición (Madrid, CEPC), p. 278.

Kavanagh, Aileen (2008): "Deference or Defiance? The Limits of the Judicial Role in Constitutional Adjudication", en: HusCROFt, G., Expounding the Constitution. Essays in Constitutional Theory (Cambridge, Cambridge University Press), pp. 184-215.

Kelsen, Hans (1942): "Judicial Review of Legislation: A Comparative Study of the Austrian and the American Constitution", en: The Journal of Politics (No 2, Vol. 4), pp. 183-200.

KLATT, Matthias (2007): "Taking Rights less Seriously. A Structural Analysis of Judicial Discretion", en: Ratio luris (№ 4, Vol. 20), pp. 506-529.

Letsas, George (2006): "Two Concepts of Margin of Appreciation", en: Oxford Journal of Legal Studies ( $\mathrm{N}^{\circ}$ 4, Vol. 26), pp. 705-732.

Martínez Estay, José (2014): "Auto-restricción, deferencia y margen de apreciación: Breve análisis de sus orígenes y de su desarrollo", en: Estudios Constitucionales ( $\left.\mathrm{N}^{\circ} 1, \mathrm{Vol} .12\right)$, pp. 365-396.

(2015): "La deferencia del Tribunal Constitucional respecto del juez de la gestión pendiente en la cuestión de inaplicabilidad", en: Estudios Constitucionales ( $\mathrm{N}^{\circ} 1, \mathrm{Vol} .13$ ), pp. 237-270.

Posner, Richard (1983): "The Meaning of Judicial Self-Restraint", en: Indiana Law Review (№ 1, Vol. 59), pp. 1-24.

RosAdO, Gema (2004): La titularidad de derechos fundamentales por la persona jurídica (Valencia, Tirant lo Blanch).

SeOANe, José A. (2009): "El perímetro de la objeción de conciencia médica" en: InDret ( $\left.\mathrm{N}^{\circ} 4\right)$, pp. 1-21.

SCHNEIDER, Hans-Peter (1982): "Jurisdicción constitucional y separación de poderes", en: Revista Española de Derecho Constitucional (Año 2, № 5), pp. 35-61.

Solove, Daniel (1999): "The Darkest Domain: Deference, Judicial Review, and the Bill of Rights", en: lowa Law Review (Vol. 84), pp. 943-1023.

Vilajosana, Josep M. (2008): Identificación y justificación del Derecho (Madrid, Marcial Pons), p. 257.

Waldron, Jeremy (2005): Derecho y desacuerdos (Madrid, Marcial Pons), p. 395.

ZAPATA, Patricio (2008): Justicia Constitucional: teoría y práctica en el Derecho chileno y comparado (Santiago, Editorial Jurídica de Chile), p. 623. 


\section{JURISPRUDENCIA CITADA \\ Corte Interamericana de Derechos Humanos}

OC-22/15, de 26 de febrero de 2016.

Corte Suprema de los Ee.UU.

United States v. Carolene Products Co., 304 U.S. 144 (1938).

First National Bank of Boston v. Bellotti, 435 U.S. 765 (1978).

Citizens United v. FEC, 558 U.S. 310 (2010).

Burwell v. Hobby Lobby Stores, Inc., 573 U.S. _ (2014).

\section{Tribunal Constitucional de Chile}

Tribunal Constitucional de 26 de noviembre del 2014, rol № 2731-2014. (Requerimiento de inconstitucionalidad presentado por un grupo de Diputados).

Tribunal Constitucional de 4 de abril del 2014, rol № 3016-16. (Requerimiento de inconstitucionalidad presentado por un grupo de Senadores). 